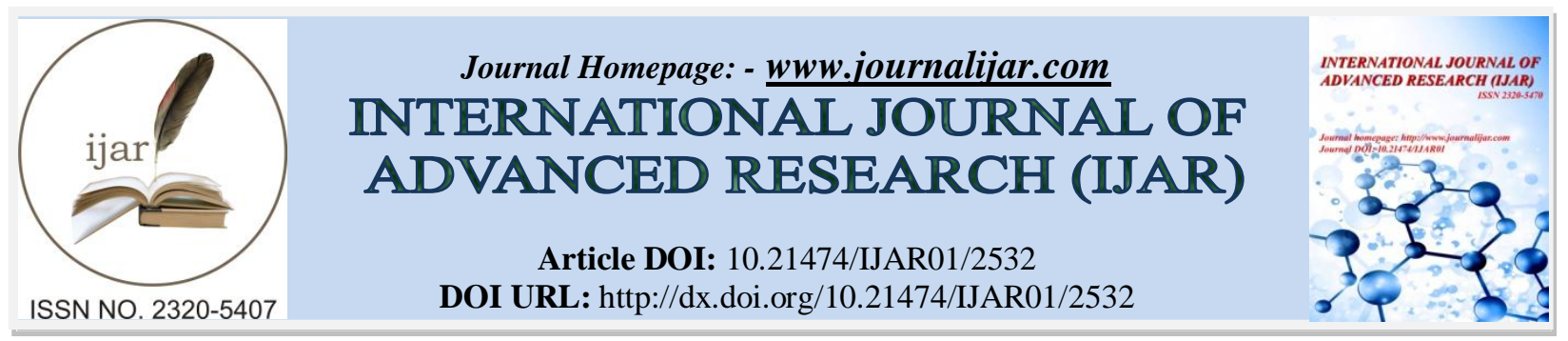

RESEARCH ARTICLE

\title{
GENDER DIFFERENCES IN MOTOR ABILITY OF CHILDREN.
}

\section{Dr. Sandip Kr. Mandal.}

Assistant Professor in physical Education; Vivekananda Mahavidyalaya; District: Hooghly; Affiliated by the University of Burdwan; W.B., India.

\section{Manuscript Info}

Manuscript History

Received: 25 October 2016

Final Accepted: 23 November 2016

Published: December 2016

Key words:-

Motor ability, motor ability variables i.e. speed, agility, power, co-ordination, Balance \& simple reaction time, gender.

\section{Abstract}

The aim of the present study was to evaluate the motor ability in respect of gender differences which age groups was 10,11 and 12 years. The number of subjects for each group was 300 boys and 300 girls for any age group. For collecting data or subjects systematic random sampling method were followed. The criterion measured on subjects which parameter was speed, agility, power, coordination, balance and simple reaction time. The mean $\pm \mathrm{SD}$, the comparative ttest of motor ability variables were calculated for the present study in respect of gender differences. Significant $(\mathrm{P}<0.05)$ in gender differences were found in six motor ability variables as F-value was greater than the tabulated value $\left(\mathrm{F}_{0.05}{ }^{1,588}=3.86\right)$. On the basis of findings the researchers were concluded that male children had better ability in all the six motor ability variables than the female children.

Copy Right, IJAR, 2016,. All rights reserved.

\section{Introduction:-}

Anyanwu (1977) conducted a study to establish physical fitness norms for Nigerian boys and girls of ages 11 through 18 years. The test items were included as agility, speed, power etc. The study were concluded: i) most of the test items the performance of the boys improved from the lower to the upper age levels, ii) the boys performed better in test items than the girls. Stone (1978) conducted research with Negro and White boys $(\mathrm{N}=112)$ aged 10 through 12years, who were arranged into four matched groups, on the basis of age and physique. He revealed that Negro boys were significantly superior in power, speed, agility, and co-ordination. Govatos (1959) were revealed about motor skills that positive relationships were existed in significant for both boys and girls. Pena et al. (2003) conducted a study on motor ability of 6-13 years school children having resident in southern Mexico revealed that sex differences varied in power and speed. Younger children and older girls performed better in the speed run.

Selection of subjects: - The sample consisted three (300) hundred boys and three (300) hundred girls in the age category of 10, 11 and 12 years were selected for the study. The number of subjects for each group was 200 (100 boys and 100 girls) for an age group. The Subjects were selected from fourteen schools from four districts as Nadia, 24-pgs (South), Kolkata and Howrah of West Bengal in India. In selecting a subject for the study, systematic random sampling procedure was followed. The willing students of the schools having roll no. 1, 6, 11, 16, 21----were considered as a subject and also they were fulfill the age criteria of the study. Age was recorded in completed years.

Selection of Test: The tests were conducted within April, 2013 in respect of motor ability variables .The motor ability tests were implemented for the purpose of the study as follows: 
Test Used

1.50-yd dash

$2.4 * 10$-yd. run

3.Standing broad jump

4. SBTfor distance

5. Stork stand

6. Electronic reaction timer
Variable Measured

Speed

Agility

Power

Co-ordination

Balance

Simple Reaction Time

Statistical techniques used: The researcher were used the statistical techniques as mean \pm S.D, ANOVA, t-test for the analyses of the study. In all the analyses, the 5\% level were consider at the statistical significant where $\mathrm{p}<0.05$.

Equipments used: The equipments were used for the collection of data as: a stop watch; $2 * 2 * 2$-inch wooden block (two); measuring tape; soft-ball throw for distance (SBT for distance); Electronic Timer.

Results and Discussion: The results and discussion on the motor ability variables as speed, agility, power, coordination, balance and Simple reaction time were presented in the forth coming paragraphs.

1. Speed: Table -1 revealed that the obtained t-value of 6.796 was greater than the tabulated value to be significant for difference between two groups in speed. The boys group was better in speed than the girls group.

According to gender, the researcher observed that the boys had better performance in speed than the girls. Research findings of other researchers observed that male children were having better speed ability than the female children at the same age group as researcher like, Toriola \& Igbokwe, 1986; Gallahue et al., 1998, which supported the similarity in result on speed in relation to gender.

Table-1:- Inter-group t-test of motor variables according to gender difference.

\begin{tabular}{|c|c|c|c|c|c|}
\hline Variables & Gender & Mean \pm S.D & Mean Differ. & S.Error & t-ratio \\
\hline \multirow{2}{*}{ Speed(sec.) } & Boys & $10.82 \pm 1.92$ & \multirow{2}{*}{0.7} & \multirow{2}{*}{0.103} & \multirow{2}{*}{$6.796^{*}$} \\
\hline & Girls & $11.52 \pm 1.84$ & & & \\
\hline \multirow[t]{2}{*}{ Agility(sec.) } & Boys & $11.57 \pm 1.09$ & \multirow{2}{*}{0.60} & \multirow{2}{*}{0.055} & \multirow{2}{*}{$10.909 *$} \\
\hline & Girls & $12.17 \pm 1.06$ & & & \\
\hline \multirow[t]{2}{*}{ Power(inch) } & Boys & $52.00 \pm 8.18$ & \multirow{2}{*}{5.79} & \multirow{2}{*}{0.426} & \multirow{2}{*}{$13.591 *$} \\
\hline & Girls & $46.21 \pm 7.48$ & & & \\
\hline \multirow{2}{*}{$\begin{array}{l}\text { Co-ordi- } \\
\text { nation(feet) }\end{array}$} & Boys & $54.48 \pm 12.18$ & \multirow{2}{*}{13.9} & \multirow{2}{*}{0.853} & \multirow{2}{*}{$16.295^{*}$} \\
\hline & Girls & $40.58 \pm 18.10$ & & & \\
\hline \multirow[t]{2}{*}{ Balance(sec.) } & Boys & $5.70 \pm 3.19$ & \multirow{2}{*}{0.70} & \multirow{2}{*}{0.187} & \multirow{2}{*}{$3.743^{*}$} \\
\hline & Girls & $5.00 \pm 3.38$ & & & \\
\hline \multirow[t]{2}{*}{ SRT(sec.) } & Boys & $0.43 \pm 0.08$ & \multirow{2}{*}{0.02} & \multirow{2}{*}{.004} & \multirow{2}{*}{$5.00 *$} \\
\hline & Girls & $0.45 \pm 0.07$ & & & \\
\hline
\end{tabular}

$\mathrm{T}_{0.05}{ }^{598}=1.96, \quad *$ Significant at 0.05 level

2. Agility: Table-1 shows the obtained t-value of 10.909 was greater than the tabulated value to be significant for difference between two groups in agility. The boys group had better agility than the girls group as per data.

3. Power: Table-1 reveals the obtained t-value of 13.591 was greater than the tabulated value to be significant for difference between two groups for power. The boys were better in power than the girls group.

The finding of the present study was also similar to the study on other population, for example, in Nigeria (Toriola and Igbokwe, 1986); Mexico (Malina, 2003) and Spain (Malleo et al., 2010). It is revealed from the findings of the study that according to gender, the boys were having more power than the girls that also observed by Morris et al., (1980); Singh (1991) and Berk (1997).

4. Co-ordination: In table-1, the obtained t-value of 16.295 was greater than the tabulated value to be significant for difference between two groups in co-ordination. The boys group had better co-ordination than the girls group according to the data.

It is revealed from the findings of the study that the co-ordination of boys was better than the girls according to gender. The investigators like Levy and Hobbes (1979); Tan et al. (2003); Eiben et al. (2005) observed better coordination ability of boys than girls.

5. Balance: Table-1 shows the obtained $t$-value of 3.743 was greater than the tabulated $t$-value to be significant for difference between two groups in balance. The boys group was better in balance than the girls as per the data. 
The investigators like Fjortoft (2000); Lejarraga et al. (2002); Lam et al. (2003); Sigmundsoon and Rostoft (2003) were observed significant difference in balance ability in respect of gender and also they observed that the girls performed better than the boys in balance.

It is revealed from the findings of the study that better performance of boys in balance than the girls in respect to gender differences.

6. Simple Reaction Time (SRT): It revealed from table-1 that obtained t-value of 5.00 was greater than the tabulated t-value to be significant for difference between two groups in simple reaction time. Hence, the boys were better performer in SRT than the girls. The investigators like Der and Deary (2006); Barrel and Debu (2004); Dane and Erzurumdugoglu (2003); Szinnai et al. (2005); Silverman (2006) observed better performance in boys in SRT.

\section{Conclusion:-}

The study was confined to the motor ability of gender differences. On the basis of findings of the present study the conclusions were drawn that in respect of gender, boys had better ability than girls in all the six motor ability variables.

\section{Recommendation:-}

i) Similar study would have been conducted on the different geographical variations; ii) A longitudinal study is needed to obtain more accurate result; iii) Similar study may be conducted on other age groups; IV) the motor ability of children would be further investigated on the basis of different cultural background.

\section{Acknowledgement:-}

The author is directly indebted to the professors in the department of physical Education of Kalyani University for their encouragement.

\section{References:-}

1. Barral, J. and B. Debu. (2004). Aiming in adults: Sex and laterality effects. Laterality: Asymmetries of Body, Brain and Cognition, 9(3): 299-312.

2. Dane, S. and A. Erzurumluoglu. (2003). Sex and handedness differences in eye-hand visual reaction times in handball players. International Journal of Neuroscience, 113(7): 923-929.

3. Fjortoft, I. (2000). Motor fitness in pre-primary school children: the Eurofit Motor Fitness Test explored on 5-7year-old children. Pediatric Exercise Science, 26(2):97-102

4. Johnson, B.L. (1970). Practical Measurement for Evaluation in Physical Education ( $3^{\text {rd }}$ Ed).USA: Burgress Publishing Company.

5. Lam, M.Y.et al. (2003). How teachers can assess kindergarten children's motor performance in Hong Kong. Early Child Development and Care, 173(1):109-118.

6. Lejarraga, H.et al. (2002). Psychomotor development in Argentina children aged 0-5 years. Pediatric and Perinatal Epidemiology, 16:47-60.

7. Malina, R.M. (2003). The typical fitness of school children resident in an urban Colonia and in rural indigenous Community in Oaxaca, Southern Mexico. AJHB, 15:800-813

8. Pena, R., M. E., Tan, W. K. and Malina, R. M. (2003). Urban-rural contrasts in the physical fitness of school children in Oaxaca, Mexico. American J. Physical Anthropol. 54: 327-336.

9. Sigmundsoon, H. and Rostoft, M. (2003). Motor development exploring the motor competence of 4-years old. Norwegian children. Scandinavian Journal of Educational Research, 47(4):451-459.

10. Silverman, I. W. (2006). Sex differences in simple visual reaction time: a historical meta-analysis (sports events). Sex Roles: A Journal of Research, 54(1-2): 57-69.

11. Szinnai, G. H.et al. (2005). Effect of water deprivation on cognitive motor performance in healthy men and women. The American Journal of Physiology, 289(1): R275-280.

12. Toriola, A.L.and Igbokwe, N.U. (1986). Age and sex differences in motor performance of pre-school Nigerian children. Jn.of Sports Science, 4: 219-227.

13. www.ncbi.nlm.nih.gov/pubmed 